\title{
Um Balanço de Parte da Teoria dos Sistemas Intencionais de Dennett ${ }^{1}$
}

\author{
Filipe Lazzeri ${ }^{2}$ \\ Universidade de São Paulo
}

\begin{abstract}
RESUMO - Dennett (1981/1987b) caracteriza sua abordagem do funcionamento dos termos intencionais (aqueles para as assim chamadas atitudes proposicionais) como um "behaviorismo lógico holista", ou versão holista de delineamentos conceituais traçados por Ryle (1949). Este artigo avalia algumas de suas possíveis contribuições e desvantagens para tais delineamentos, e algumas consequências para sua proposta de utilização destes termos em psicologia. Argumenta-se que a abordagem não se mostra mais plausível do que a de seu predecessor, caso a dimensão mentalista que lhe acrescenta seja equivocada, e que de fato este é o caso. Disso resulta que suas contribuições e proposta correlata devem ser entendidas com independência daquilo que tal dimensão implica. Uma alternativa não-mentalista, baseada no modelo selecionista de Skinner, para uma eventual adoção dos termos intencionais em psicologia, é brevemente discutida.
\end{abstract}

Palavras-chave: termos intencionais; Dennett; Ryle; seleção pelas consequências; behaviorismo.

\section{An Assessment of a Part of Dennett's Intentional Systems Theory}

\begin{abstract}
Dennett (1981/1987b) characterizes his approach as to how intentional terms (those for the so called propositional attitudes) work as a "holistic logical behaviorism," or a holistic version of some of Ryle's (1949) conceptual remarks. This paper examines possible contributions and disadvantages of Dennett's approach, as well as the consequences of this proposal in relation to the employment of intentional terms in psychology. It is argued that Dennett's approach does not turn out to be more accurate than his predecessor's, since the mentalistic dimension it adds to the latter is erroneous. Accordingly, Dennett's contributions and related proposal should be understood without the implications of this dimension. Anon-mentalistic alternative, based upon Skinner's selectionist model, for eventually adopting intentional terms in psychology is briefly discussed.
\end{abstract}

Keywords: intentional terms; Dennett; Ryle; selection by consequences; behaviorism.

Termos psicológicos intencionais (entendidos aqui como aqueles para as assim chamadas atitudes proposicionais), tais como 'opinião', 'expectativa' e 'querer', são termos que, consoante se tem reputado em discussões recentes, remetendo a Brentano (1874/1995), dizem respeito a fenômenos psicológicos que exibem intencionalidade, no sentido de serem sobre algo (acha-se que algo é o caso, espera-se por algo, etc.) e este algo pode não ser, ou vir a ser, efetivamente o caso. Diz-se que tal propriedade se traduz na opacidade referencial dos enunciados compostos por tais termos (Quine, 1960), ou seja, em mostrarem-se recalcitrantes à lei de substituição de idênticos (por exemplo, de "Édipo quer casar-se com Jocasta", não necessariamente se seguiria "Édipo quer casar-se com sua mãe", embora Jocasta seja mãe de Édipo). Há controvérsia sobre a correção da tese de Brentano de que todo termo intencional é termo psicológico (e que toda intencionalidade é propriedade de eventos psicológicos). Por brevidade, emprega-se ao longo deste artigo a expressão 'termos intencionais' (e expressões correlatas), ao invés de

1 Gostaríamos de agradecer, de modo especial, a Eros M. de Carvalho, Paulo C. Abrantes e Jorge Oliveira-Castro, pelos comentários a versões anteriores do material que compõe o presente trabalho. Também à CAPES, pelo apoio (bolsa de mestrado na UnB) com que este trabalho contou. A responsabilidade pelo conteúdo é apenas do autor.

2 Endereço para correspondência: Universidade de São Paulo, Departamento de Filosofia/Faculdade de Filosofia, Letras e Ciências Humanas, Av. Prof. Luciano Gualberto, 315 (Cidade Universitária). São Paulo, SP. CEP 05508-900. E-mail: filipelazzeri@gmail.com 'termos psicológicos intencionais', ainda que sem se pressupor a tese de Brentano.

Em "Three Kinds of Intentional Psychology", Dennett (1981/1987b) afirma que sua teoria dos sistemas intencionais, no que tange à interpretação do funcionamento dos termos intencionais, é uma forma de "behaviorismo lógico holista", ou versão holista da abordagem desenvolvida por Ryle (1949). Uma pergunta que se coloca, então, para quem vê em Ryle (1949) uma abordagem razoável (embora certamente podendo ser complementada) sobre tais termos, é a de se a de Dennett apresenta vantagens sobre ela.

Que haja em Ryle (1949) um behaviorismo lógico e não-holista, porém, trata-se de algo que merece qualificação, a começar pelo fato de Ryle não ter proposto análises reducionistas associadas ao behaviorismo lógico (como, por exemplo, aquele de Hempel, 1935/1980), mas, antes, tentativas de clarificação do funcionamento dos conceitos em questão (e dos conceitos psicológicos comuns de modo mais geral), como empregados ordinariamente. Acrescenta-se ainda o fato de Ryle (1937/2009) desacreditar a formulação de ismos em filosofia, salientando que deturpam o que entende como sendo o foco maior da área - as clarificações conceituais via argumentos cogentes. Entretanto, pelo menos sob certa (talvez natural) interpretação, sua abordagem possui uma "similaridade de família" (Wittgentein, 1953) com algumas análises behavioristas sobre os mesmos, particularmente com as de Skinner (1974) e, mais recentemente, as de Rachlin (1994). O autor evita dizer-se um behaviorista, mas parece referir-se ao behaviorismo de tendência watsoniana, que 
possui uma feição "metodológica" e estipulativa (cf. Ryle, 1949, cap. 10) e com o qual discorda por basear-se em um modelo mecanicista do comportamento (cf. Ryle, 1949, cap. 3) e caracterizar a noção de pensamento como uma forma de verbalização (cf. Ryle, 1979).

O presente trabalho tem dois objetivos. O primeiro é propor uma resposta condicional à questão de se a abordagem de Dennett possui vantagens sobre aquela que encontramos em Ryle (1949), a saber, que: se o elemento mentalista da abordagem de Dennett revela-se equivocado, então ela não se mostra mais satisfatória do que a de Ryle, e muito de sua contribuição para esta consiste em reiterações, com novos argumentos e elucidações, dos delineamentos já nela presentes. O segundo objetivo do trabalho é mostrar algumas implicações desta resposta para a visão de Dennett sobre o lugar dos termos intencionais em uma psicologia naturalista. Confere-se um sentido não-mentalista aos contornos de sua proposta, combinando a abordagem de Ryle com o modelo da seleção pelas consequências de Skinner (1981/1988). Desta maneira, vai-se ao encontro de algumas considerações de Rachlin (1994) a respeito da utilização deste vocabulário em psicologia, e, por outro lado, contrapõe-se a certas considerações de Foxall (2004, 2007).

O termo mentalismo é empregado neste artigo em uma acepção próxima de Skinner (cf. Carvalho Neto, 2001; Moore, 2008), em particular em relação aos termos em questão. Assim, uma perspectiva mentalista de seu funcionamento é qualquer uma segundo a qual as funções que eles têm de explicar e predizer o comportamento são desempenhadas pela remissão a (pressupostas) correspondentes entidades (internas) iniciadoras do comportamento, localizados em alguma parte do organismo ou sistema, sejam estados, processos ou eventos com um estatuto mental, neurofisiológico e/ou similar.

$\mathrm{O}$ artigo começa com uma revisão da teoria dos sistemas intencionais de Dennett, com foco, respectivamente, em sua abordagem sobre estes conceitos e em sua proposta de utilização deles em psicologia. Em seguida, apresenta-se uma avaliação da abordagem, por meio de uma delimitação dos aspectos que claramente adiciona às análises de Ryle - o funcionalismo e o mentalismo sendo ressaltados como dois deles - e delimitação daqueles que já estão presentes nestas análises, levantando-se objeções ao aspecto mentalista. Por fim, são averiguadas implicações para a teoria dos sistemas intencionais quanto à utilização do vocabulário intencional em psicologia, e esboçados contornos alternativos à proposta.

\section{$O$ funcionamento dos termos intencionais segundo Dennett}

Para Dennett, os termos intencionais cumprem, em geral, as funções de explicar e predizer comportamentos. Fazem-no pela atribuição de estados mentais correspondentes - desejos, propósitos, suposições, etc. - cuja posse pareça ser razoável racionalmente, dadas as circunstâncias e a história do sistema (Dennett, 1971/1978a, 1996).

Dennett utiliza a expressão 'sistema intencional' para se referir aos sujeitos das predicações intencionais que efetivamente as satisfazem, não restringindo o tipo de objeto que possa em princípio ter seu comportamento explicado ou predito desta maneira. Por exemplo, não só seres humanos podem ser sistemas intencionais, mas também outros organismos, seres inorgânicos como os computadores domésticos, etc. $\mathrm{O}$ fato de os sistemas intencionais poderem ser de tão grande diversidade física e de projeto ('design') - constituição funcional - deve-se a que, segundo o autor, os termos intencionais são empregados com independência de suposições sobre os mecanismos físicos subjacentes à causação dos comportamentos dos sistemas - tais como as leis naturais envolvidas e as constituições físicas dos sistemas -, bem como sobre a constituição funcional deles (Dennett, 1971/1978a, 1996). Dennett aprecia dar como exemplo um computador enxadrista, porque o comportamento de jogador que este sistema exibe pode ser predito através de atribuições intencionais claramente sem apelo ao que está especificamente ocorrendo em sua maquinaria e às linhas específicas de como está programado para jogar. Há apenas uma suposição geral sobre a física dos sistemas e uma sobre sua constituição funcional, a saber, respectivamente, a suposição de que eles não possuem anomalias e a de que agem racionalmente, pelo que se entende que agem segundo os atributos intencionais que se pressupõe que tenham. Embora não seja muito comum o emprego dos termos intencionais a todos estes tipos de sistemas, sua lógica - cujos limites o autor explora - o admite.

A esta estratégia explicativa e preditiva, Dennett chama de postura intencional. Ela contrasta com a postura física, estratégia que faz explicações e predições com base nos mecanismos físicos envolvidos na causação dos eventos - por exemplo, dizer-se que uma pessoa ergueu o braço porque certos mecanismos neurais foram disparados; que uma bola passou a cair por causa da força da gravidade, do ângulo com que foi lançada, etc. Também, com a postura de projeto, que o faz com base em considerações sobre os aspectos funcionais dos sistemas - por exemplo, dizer-se que uma pessoa ergueu o braço por este comportamento ter certa função produzida por tal e tal história de reforço; que o computador enxadrista fará determinada jogada por ter tais e tais linhas de programação e certos comandos terem sido executados pelo adversário humano. A postura física aplica-se em princípio a qualquer objeto físico, mas ela é útil, comumente, apenas para eventos que não envolvem projetos. Para os casos de sistemas projetados, costuma ser desnecessária a consideração de pormenores físicos, porque uma tal consideração demanda relativamente muito tempo e sem haver ganho de inteligibilidade (salvo quando há anomalias físicas nos sistemas, em que a postura física é também útil). É consideravelmente mais simples e inteligível dizer-se, por exemplo, que um despertador tocará por causa de certos ajustes feitos nele do que se apelar para os processos físicos de suas válvulas e variáveis análogas. Também seria mais útil dizer-se que o computador enxadrista executaria determinada jogada por ter certas intenções e suposições (por exemplo, sobre os melhores movimentos e sobre as estratégias do oponente) do que tentar apelar a processos de sua maquinaria, e, inclusive, do que apelar para as linhas de sua programação. O que vem a calhar (pragmaticamente) em casos de sistemas projetados - se a postura de projeto ou a postura intencional - depende da complexidade do sistema. Para Dennett (1971/1978a, 1981/1987a, 1996), quanto 
mais complexo o sistema, maior torna-se a premência de empregar-se os termos intencionais - a postura de projeto não muito diferentemente da postura física já demandando tempo demais e sem ganho de percepção do comportamento que se apresenta.

Ainda que não se baseie em suposições sobre aspectos específicos dos projetos dos sistemas, a postura intencional está ancorada nos projetos. Não é por acaso que ela funciona: desejos, intenções, crenças, etc., estão relacionados às constrições de adaptação do sistema ao ambiente e, com efeito, são atribuídos com base na história do sistema e nas circunstâncias em que ele se insere (cf. Dennett, 1981/1987a, 1981/1987b). Quando os termos intencionais são aplicados sem relativo ganho de poder preditivo e de inteligibilidade (comparativamente às outras estratégias) - como, por exemplo, para se explicar ou prever um raio -, eles não se aplicam genuinamente. Em outras palavras, apenas são sistemas intencionais aqueles sistemas cujos comportamentos tais atribuições contribuem para serem percebidos e preditos, e tais sistemas, em geral, possuem projetos.

Dennett (1969, 1981/1987b) considera que as predicações intencionais capturam, de modo aproximativo, determinadas funções realizadas por estruturas dos sistemas. A abordagem do autor compartilha com o funcionalismo em geral a visão de que as predicações em questão designam funções relacionadas à economia causal - ou seja, à produção de comportamentos e de outras funções correspondentes a atributos intencionais - dos sistemas, mas, tal como a abordagem de Millikan (1984), difere de outras versões do funcionalismo por conceber estas funções no sentido teleológico-biológico do termo (o que Millikan chama de função própria). Há discussão em torno da melhor maneira de analisar-se a noção (cf. Millikan, 1989; Wright, 1973), mas Dennett (1981/1987b, p. 64, pp. 74-75, p. 81) menciona particularmente a de Millikan. A ideia é que as funções capturadas por tais predicações resultam de interação seletiva, filogenética ou ontogenética, e estão relacionadas à contribuição das entidades que as realizaram (historicamente) - no caso, estruturas neurais ou similares - para a sobrevivência ou reprodução do sistema dos quais estas são parte. As funções não necessariamente correspondem aos papéis causais que estão sendo desempenhadas pelas estruturas, como concebe o funcionalismo tradicional (tanto o de máquina de Turing como o reducionista), mas, antes, àqueles que desempenharam em processos que os selecionaram. No caso das funções capturadas pelas atribuições intencionais, na visão de Dennett, podem ser produtos não só de uma história seletiva da espécie ou uma história de reforço, mas também de uma evolução ocorrida no cérebro ou "ambiente interno" (mais adiante este ponto é retomado).

O modo aproximativo das atribuições intencionais é bastante enfatizado por Dennett (1981/1987b). Elas possuem, segundo o autor, um caráter idealizador, abstrato $e$ instrumentalista. O caráter idealizador é o de que elas são feitas sob a pressuposição de que o sistema age de acordo com os respectivos estados mentais que lhe são atribuídos. Os sistemas nem sempre são tão "racionais", já que agem por vezes de modo contraditório com o que pensam e desejam, e tampouco são bastante "epistemicamente espertos" a ponto de considerarem todos os aspectos relevantes do ambiente em que estão e sua própria história (na base do que as atribuições são feitas). Por caráter abstrato, o autor entende que as atribuições são feitas com independência da consideração de aspectos da física e do projeto dos sistemas. Seu caráter instrumentalista é o de que, desta maneira, elas não supõem designarem estados e processos discretos, menos ainda vis-à-vis. Os conceitos intencionais não são como aqueles para vírus e enzimas, ou qualquer outra entidade que possua um caráter episódico, não-disposicional. Antes, eles desempenham um papel análogo ao de conceitos como o de torque e paralelograma de forças. Para ilustrar este último aspecto, Dennett (1981/1987b) menciona a distinção de Reichenbach (1938) entre dois tipos de referências para termos teóricos: as entidades illata, que são tomadas como realidades concretas, e as entidades abstracta, que são apenas construtos lógicos para efeito de cálculo. Na perspectiva de Dennett, os conceitos intencionais estão para abstracta, e não illata. Tomar-se atributos intencionais como entidades internas discretas seria como se interpretar literalmente os eixos de um cálculo vetorial.

Este caráter "instrumentalista" não significa necessariamente uma forma de antirrealismo a respeito dos conceitos intencionais. Para o autor, um tal instrumentalismo é algo que muitos realistas aceitam, na medida em que não interpretam conceitos como o de torque e paralelograma de forças de maneira literal, o relevante sendo que capturem, ainda que de uma maneira aproximativa e indireta, forças causais subjacentes aos eventos que pretendem explicar ou predizer. É neste sentido que Dennett (1991) qualifica sua abordagem como sendo um "realismo brando" sobre as atribuições intencionais. Estados e processos cerebrais e processos de informações são tomados como realidades concretas, as quais as atribuições intencionais - que são feitas em massa (ou seja, não isoladamente) - efetivamente os tangenciam (ou "mensuram", na expressão que Dennett toma emprestado de Churchland, 1979), quando contribuem para a percepção de um padrão comportamental e a sua predição. O realismo é de tipo moderado porque considera implausível, entretanto, que haja correspondências vis-à-vis entre as atribuições e entidades discretas, e porque admite a possibilidade de que duas atribuições contraditórias possam ser simultaneamente verdadeiras - ao serem igualmente bem-sucedidas em predizer padrões comportamentais.

\section{A postura intencional em psicologia}

O autor não descarta a possibilidade de haver alguns casos de atribuições intencionais ordinárias em que suponham remeter a entidades illata (cf. Dennett, 1981/1987b, pp. 5657). Mas, como seu interesse maior está em explorar o que considera "haver de melhor" na "psicologia de senso comum" para finalidades científicas, Dennett (1981/1987b) sugere aquilo que chama de teoria dos sistemas intencionais, que é

estritamente abstrata, idealizadora, holista, instrumentalista [...].

[É] uma forma de behaviorismo lógico holista, porque lida com a predição e a explicação a partir de perfis de tipo crença-desejo das ações dos sistemas inteiros [...]. O sujeito de todas as atribuições intencionais é o sistema como um todo [...], ao 
invés de alguma de suas partes, e crenças e desejos individuais não são atribuíveis isoladamente, com independência de outras atribuições de crenças e desejos. O último ponto distingue a teoria dos sistemas intencionais bem claramente do behaviorismo lógico de Ryle, que contraiu o ônus impossivel de caracterizar crenças (e outros estados mentais) individuais como disposições individuais para comportamento manifesto. (pp. 57-58)

Ou seja, a teoria dos sistemas intencionais é uma proposta de emprego dos termos intencionais em psicologia, tomados em suas características acima descritas (seu caráter idealizador, abstrato e instrumentalista), inclusive seu caráter holista (de serem feitas em massa), independentemente de haver eventuais exceções no emprego ordinário deles. Além disso, as atribuições intencionais recaem sobre o sistema como um todo. $\mathrm{O}$ autor alega que elas assim concebidas estão de acordo com o "behaviorismo lógico" de Ryle, com a diferença de que estaria considerando a dimensão holista delas, ou seja, que elas não se deixam reduzir a predicações que não incluam outros termos intencionais.

O emprego ordinário dos termos intencionais (a "postura intencional") não faz, em geral, compromisso com causas específicas, pois não ocorre pela menção a elementos físicos ou funcionais. No entanto, como ao se mostrarem preditivas e darem sentido àquilo que um sistema faz, as atribuições intencionais tangenciam elementos difusos da economia causal dos sistemas (uma economia de funções próprias), há correlações aproximadas e não-redutivas que podem ser feitas entre elas e estes elementos difusos. Dennett atribui ao que chama de psicologia cognitiva subpessoal a tarefa de buscar tais correlações, tarefa equivalente à busca pelos mecanismos funcionais de causação dos comportamentos ditos "inteligentes" e pela "realização real dos sistemas intencionais" (Dennett, 1981/1987b, p. 57). Em outras palavras, caberia a este ramo da psicologia elaborar e testar modelos dos processos mecânicos internos que "imitam" a semântica das atribuições intencionais.

Segundo propõe Dennett (1981/1987b, pp. 61-63), o trabalho da psicologia cognitiva subpessoal requer ser balizado pela aplicação da teoria dos sistemas intencionais. $\mathrm{O}$ cérebro é visto pelo autor como uma "máquina sintática", cuja semântica não é oriunda de seus próprios processos, mas das interpretações a partir da postura intencional. Ou seja, os conteúdos (ou semântica) das predicações intencionais não são contrapartidas de conteúdos internos dos sistemas, mas projeções - um "revestimento linguístico" ("linguistic overlay') - feitas com base na observação do comportamento do sistema e em aspectos do ambiente e da história do sistema (Dennett, 1969, pp. 78-80). Portanto, não há como se determinar os atributos intencionais de um sistema pela simples observação de propriedades internas e locais dele. A determinação das competências, ou funções próprias, dos sistemas requer que seus comportamentos e o ambiente maior sejam levados em conta. Isto é natural, dado que as competências, nesta visão, estão relacionadas à adaptação dos sistemas às condições ambientais, e, em longo prazo, à sua sobrevivência e reprodução.

Os perfis ou caracterizações de um animal-ou, se for o caso, um sistema inanimado - a partir da postura intencional podem ser vistos como aquilo que os engenheiros chamariam de um conjunto de specs - especificações para um dispositivo com uma certa competência geral de processo de informação. [...] [Estes perfis dizem] qual informação deve poder ser recebida, usada, lembrada, transmitida pelo sistema. Alude [m] às maneiras segundo as quais as coisas das cercanias devem ser representadas [...]. Tais specs intencionais, então, estabelecem uma tarefa de projeção para o próximo tipo de teórico, o projetista de sistemas de representação. [Em nota] [Ou seja, a] teoria dos sistemas intencionais especifica uma máquina semântica que deve ser realizada [...] por uma máquina sintática projetada pelo psicólogo cognitivo subpessoal. (Dennett, 1983/1987c, pp. 255-256)

O uso da teoria dos sistemas intencionais seria útil, por exemplo, ao etólogo, que, em suas pesquisas de campo, delimitaria por via da postura intencional as funções próprias, ou competências, dos sistemas intencionais em estudo. A partir deste trabalho, encontrar-se-iam as constrições para a tarefa da psicologia cognitiva subpessoal de projetar máquinas que imitem as competências dos sistemas estudados.

Dennett argumenta que o emprego do vocabulário intencional em psicologia é uma necessidade prática, com base na visão de que a percepção dos padrões comportamentais inteligentes depende das atribuições de conteúdo e de que se trata de um vocabulário único para sua predição. $\mathrm{O}$ autor critica tanto a rejeição deste vocabulário por Skinner (1971) como por Churchland (1979). De um lado, alega que a tentativa de interpretação dos padrões em termos de contingência de reforço deixa de especificar o que é aprendido, e, por isso, segundo ele, o analista do comportamento na verdade pressupõe tacitamente a interpretação intencional (cf. Dennett, 1969, pp. 33-34, 1971/1978a). Além disso, a predição em termos de contingência tríplice dependeria do conhecimento das histórias de reforço relevantes, cujo acesso frequentemente não está à mão (cf. Dennett, 1978b, pp. 67-69). De outro lado, a tentativa de interpretação e de predição inteiramente em termos neurofisiológicos é como querer interpretar e predizer eventos envolvendo objetos de tamanho médio olhando-se para seu nível microfísico; não se prediz o comportamento de um computador enxadrista mencionando-se seus processos ao nível do hardware (cf. Dennett, 1981/1987a, pp. 25-27, 1991, pp. 50-51). As vantagens da postura intencional ficam claras ao se considerar o contraste entre ela e a posturas física e de projeto.

\section{Comparação com a abordagem de Ryle e ponderação do elemento mentalista}

A abordagem de Dennett possui as seguintes similaridades e respectivas diferenças com a de Ryle:

(i) Caráter disposicional dos termos intencionais. Como vimos, Dennett sustenta que os termos em questão não designam entidades discretas ou específicas, mas, antes, apenas legitimam inferências sobre prováveis comportamentos dos sistemas, ao se mostrarem preditivas. Nos termos de Ryle (1949), este tipo de conceito compõe enunciados que funcionam como "bilhetes para inferências" (inference-tickets) de curto ou longo prazo, que se deixam analisar em enunciados hipotéticos ou semi-hipotéticos relacionado contextos e 
comportamentos (geralmente, mas nem sempre, manifestos) associados a tais contextos. Como salienta Tanney (2009), isso significa que os termos intencionais desempenham suas funções por contextualizarem comportamentos prováveis, ocorridos e/ou que estão ocorrendo. A diferença entre as abordagens é que a de Dennett possui uma conotação mentalista, pressupondo que estes termos funcionam como conceitos teóricos abstracta, atribuições de conteúdo a processos difusos da economia funcional dos sistemas, que não só contextualizariam as ações, mas designariam, ipso facto, ainda que indiretamente, funções próprias realizadas por estruturas neurais ou similares dos sistemas.

(ii) Externismo. Segundo Ryle, as predicações intencionais possuem como critério (Wittgenstein, 1953) de aplicação relações entre contextos e comportamentos, inclusive a maneira como são conduzidos, possivelmente dentro de uma escala larga de tempo. Embora as predicações sejam "abertas", ou seja, possam satisfeitas por inúmeros comportamentos e de, eventualmente, uma similaridade apenas vaga ("de família"), geralmente a observação de algumas poucas correlações comportamentais-contextuais basta para estabelecer-se a aplicabilidade ou não de atribuições particulares. Algo semelhante (embora com uma diferença crucial) é sustentado também por Dennett, ao chamar atenção para o fato de que as atribuições a partir da postura intencional definem-se com base na consideração da história interativa do sistema e do ambiente em que se insere, e também para o fato de que a força preditiva delas estabelece sua aplicabilidade. As abordagens diferem, novamente, em que, na de Dennett, para além das relações entre contextos e comportamentos, as atribuições intencionais designam mecanismos internos de controle do comportamento. (Pondera-se, em seguida, que isso parece tornar redundante seu externismo.)

(iii) Múltipla exemplificação das predicações intencionais. Uma vez que o critério de satisfação das predicações intencionais é constituído fundamentalmente de relações deste tipo, e considerando-se que, em princípio, diferentes tipos de estruturas físicas podem realizar os padrões comportamentais, tais predicações são multiplamente exemplificáveis. Ou seja, uma atribuição como " $x$ querer obter alimento" pode ser verdadeira a respeito de sistemas de diversas constituições físicas, desde um ser humano, um rato, ou qualquer outro sistema particular que realize comportamentos relevantes (quem sabe um robô suficientemente complexo), sob os contextos apropriados, aos quais costumamos associar uma tal atribuição. Por exemplo, " $x$ querer obter alimento" é potencialmente satisfeita por um sistema $x$ que, dada a presença de certos alimentos, dispensa seu tempo na obtenção de algum, e/ou, sob condição de privação por um tempo longo relativamente à frequência em que costuma se alimentar, vai até a um local de alimentação (como, por exemplo, um restaurante, no caso de um ser humano), e/ou etc. Em termos ontológicos, sistemas de diversas constituições físicas podem, em princípio, ter um mesmo tipo de atributo intencional. Esta tese é geralmente associada ao funcionalismo - a partir da crítica de Putnam (1960) à assim chamada teoria da identidade de tipos -, mas, a rigor, ela está implícita em Ryle (1949), embora sem que atributos intencionais sejam entendidos como algo fundamentalmente interno, realizado por estruturas de algum tipo (cf. Rachlin, 1994). (iv) Irredutibilidade sem dualismo. Características como (i)-(iii), dentre outras, evidenciam que os conceitos intencionais operam de uma maneira dissimilar à linguagem da "postura física". Dennett (1969) também argumenta em favor desta tese com base no traço holista destes conceitos e seu reflexo na opacidade dos respectivos enunciados. Tais conceitos são empregados na inferência de fatores que estão para além de coisas como estados cerebrais e movimentos corporais, a saber, dizem respeito a relações molares envolvendo o sistema e o ambiente. Assim, este ir além não é inferir eventos ocultos, em um ambiente recôndito, não-natural. Dennett, porém, sugere que as atribuições respectivas são como uma espécie de cálculo instrumental de eventos de um "ambiente interno", o que representa um compromisso com uma visão em certa medida referencial delas, da qual os delineamentos de Ryle são isentos (cf. Tanney, 2009), e um foco em causas internas.

Um quinto aspecto conceitual com o qual, sustentamos, ambas as abordagens estão em conformidade é a feição holista das atribuições intencionais. Muito embora Dennett (como vimos acima) supõe que acrescente este elemento à abordagem de seu predecessor, isso não é inteiramente correto, pois não há qualquer motivação reducionista da parte da abordagem de Ryle, que está voltada para o emprego comum dos termos em questão, o qual exibe um traço holista bastante claro. Por exemplo, do fato de uma pessoa tencionar fortemente tornar-se um físico, pode-se inferir provavelmente com sucesso que, se ela também acha que fazer pós-graduação na área é uma condição necessária para isso, então ela quer fazer pós-graduação na área, gosta de física, não deseja optar por opções que lhe são menos interessantes, etc. A questão é que, do fato de uma predicação intencional legitimar uma cadeia inferencial de outras predicações intencionais, não se segue o mentalismo. A cadeia leva-nos a mais e mais contextualização da conduta do agente, e não a entidades internas iniciadoras da conduta. Uma outra diferença com a abordagem de Dennett a esse respeito é de que, nesta, a feição holista do vocabulário intencional tem um foco maior. Ela é vinculada às considerações de Quine (1960) sobre a "indeterminação da tradução": diferentes "perfis intencionais", mesmo incompatíveis, podem, em princípio, ter igual poder preditivo, e, em tal caso, não há autoridade última sobre qual deles deve ser aplicado. Ambos os perfis são aplicáveis genuinamente (cf. Dennett, 1991). Isto é uma novidade argumentativa (que consideramos plausível), mas não uma modificação da perspectiva de Ryle de um reducionismo para um holismo.

Ademais, curiosamente, a abordagem de Dennett, na verdade, não se assemelha à de Ryle quanto à mereologia (a lógica das partes e do todo) dos termos intencionais, muito embora Dennett chegue a afirmar, em certo momento (como vimos), que eles recaem sobre o sistema como um todo. Como aponta Foxall (2007), ocorre que Dennett não é coerente com a referida afirmação, ao assumir sub-repticiamente que tais conceitos podem ser empregados também a partes dos sistemas. Com efeito, Dennett não vê problemas em que a psicologia cognitiva subpessoal postule homúnculos como subsistemas intencionais (dotados de atributos intencionais) para fins de modelagem de projetos (cf. Dennett, 1981/1987b, pp. 73-74). Mais recentemente, comentando as considerações levantadas por Bennett e Hacker (2003) acerca da mereologia 
de tais conceitos, Dennett (2007) assevera que, a partir de sua perspectiva, são legítimas, em princípio, as atribuições intencionais a partes dos sistemas (por exemplo, ao cérebro e suas partes), tão logo exibam "comportamentos" suficientemente semelhantes aos dos sistemas como um todo.

Em resumo, a teoria dos sistemas intencionais preserva as distinções que encontramos na abordagem de Ryle das características disposicional, contextualizadora das atribuições intencionais, externista, de serem multiplamente exemplificáveis e irredutíveis. Além disso, dá uma ênfase ao caráter holista delas. Mas o faz imbuindo estes pontos de uma dimensão mentalista e funcionalista.

\section{Ponderação do elemento mentalista da abordagem de Dennett}

Considerando-se que o elemento funcionalista, em seu fundamental, não é inerentemente mentalista, o elemento que fundamentalmente distingue as perspectivas acima comparadas é o mentalismo. Portanto, se a abordagem de Ryle representa melhor o funcionamento dos conceitos intencionais, então é por estar livre dos possíveis problemas associados ao mentalismo. Apontam-se três destes possíveis problemas a seguir.

Uma primeira objeção pode ser levantada com base naquela de Bennett e Hacker (2003) ao erro mereológico de categoria, reformulando-a (embora sendo a mesma em seu fundamental) em questionamento do elemento mentalista. Se o mentalismo sobre os termos intencionais fosse correto, então a mereologia das predicações intencionais seria tal que elas recairiam primariamente sobre uma parte do sistema. Suponha-se, por hipótese, que o fosse. Mas se a mereologia das predicações intencionais assim fosse, então faria sentido sua aplicação a partes de sistemas. Ora, não faz sentido tal aplicação. Logo, a partir da hipótese do mentalismo, segue-se uma contradição (de que faz e não faz sentido a aplicação das predicações intencionais a partes de sistemas). Portanto, o mentalismo sobre os termos intencionais não é correto (reductio ad absurdum).

Em outras palavras, se fosse cabível dizer-se, por exemplo, que cérebros querem, têm opiniões, etc., como é em princípio possível a partir da teoria dos sistemas intencionais, isso estaria de acordo com a lógica da aplicação dos termos em questão, o que é falso: eles só se aplicam com sentido (salvo metaforicamente) apenas ao organismo - ou outro tipo de sistema que seja - como um todo. Diz-se, por exemplo, que Pedro tenciona ir à biblioteca pela manhã, e não que uma parte de seu cérebro o tencione; diz-se que um pombo quer pousar sobre o galho de determinada árvore, e não que seu cérebro o queira. É um nonsense a aplicação dos termos intencionais ao cérebro ou qualquer outra parte similar de um organismo ${ }^{3}$. Se tais premissas estiverem corretas, como o cremos, segue-se a conclusão de que o mentalismo é uma suposição equivocada.

3 Cabe a observação de que, por outro lado, intencionalidade (no sentido de Brentano), ao nosso ver, faz sentido, em princípio, ser atribuída a partes de sistemas, subpartes, e assim por diante. O que não faz sentido é a aplicação de predicados psicológicos intencionais, que são a categoria em questão no presente trabalho.
Uma segunda ponderação é de que o elemento mentalista da perspectiva de Dennett parece ser redundante. Do fato de uma pessoa ter conhecido vários prédios e atividades de uma universidade, pode-se inferir com sentido que ela conheceu a universidade. No entanto, não se pode inferir que conheceu os prédios, as atividades $e$ a universidade. Pois não utilizamos o termo 'universidade' para indicar algo paralelo aos prédios e atividades acadêmicas (e outros componentes), mas para indicar um conjunto de tais coisas (Ryle, 1949). Em outras palavras, 'universidade' não é da mesma categoria que os termos correspondentes a tais coisas, e seria redundante dizer-se que ele seja algo para além delas em suas relações relevantes. Parece que algo análogo deve ocorrer com as atribuições intencionais se a tese externista, tal como mantida por Dennett, for o caso, uma vez que, segundo ela, tais atribuições são verdadeiras ou falsas conforme as relações ambientais e comportamentais relevantes. No entanto, a partir da premissa mentalista simultaneamente assumida por Dennett, seria logicamente legítimo dizer-se que um sistema exibiu e/ou exibiria tais e tais condutas, sob os contextos que lhe constituem ocasião, e exibiu e/ou exibiria tais e tais crenças, expectativas, etc. Pois, segundo esta premissa, atributos tais estão para além das relações entre condutas e contextos (diz-se que são "estados mentais", etc.). Se esta analogia estiver correta, o elemento mentalista mostra-se redundante.

Uma das raízes deste elemento na teoria de Dennett é a suposta necessidade de postular-se causas mentais para dar-se conta de certas novidades comportamentais. As seleções filogenética e operante seriam insuficientes para se explicar comportamentos que não possuem uma história de seleção explícita de algum destes tipos. Ter-se-ia de postular uma pré-seleção em um "ambiente interno" (cf., por exemplo, Dennett, 1996). Os seres humanos e alguns outros vertebrados não seriam apenas “criaturas skinnerianas”, mas também "popperianas", alguns comportamentos dos quais seriam pré-selecionados ou extintos internamente, conforme seus desejos, opiniões e similares. O autor, tomando o exemplo, a partir de Skinner (1953, p. 177), de uma pessoa que nunca tenha aprendido a entregar a carteira a um assaltante que lhe exigisse, diz que a pessoa exibiria ipso facto um comportamento não-determinado por seleção operante - que não se deixaria explicar por referência a uma história de reforço (Dennett, 1978b, p. 67).

Aqui entra uma terceira ponderação ao elemento mentalista: tal argumento de Dennett em justificação deste elemento revela-se fraco, de modo que, mais uma vez, tem-se que se trata de um elemento redundante e supérfluo. $\mathrm{O}$ argumento falha em sua premissa de que é necessário que um comportamento operante seja resultado de uma história de reforço específica, direta. Cleaveland (2004) obtempera que o operante pode ser uma "agregação ['cooption'] de elementos pré-existentes no repertório comportamental do organismo" (p. 77). A pessoa pode nunca ter antes entregue sua carteira diante de ameaça ou ter sido instruída explicitamente para fazê-lo, mas é bastante provável que seu repertório comportamental inclua o comportamento de entregar um objeto diante de ameaça ou autoridade, reforçado no passado. (Segundo Cleaveland, isso é o equivalente ontogenético de uma exaptação.) Então, a conduta daquela pessoa diante da ameaça do assaltante, como apontam Baum e Heath (1992, 
p. 1315), seria um comportamento de seguir regra (Skinner, 1966/1969), ou seja, a ameaça funcionaria como um estímulo discriminativo sinalizador de uma contingência de reforço negativo. Portanto, não é preciso ir-se além das contingências de reforço e de punição para se explicar novidades comportamentais como a mencionada pelo autor, e uma motivação principal de seu mentalismo mostra-se equivocada.

Se o mentalismo mostra-se implausível, à luz de (inter alia) ponderações como estas, tem-se que não representa algum ganho às delineações conceituais traçadas por Ryle. Assim sendo, a teoria dos sistemas intencionais contribui na clarificação dos termos intencionais basicamente ao retificar, mas com independência de seu aspecto mentalista, algumas destas delineações, tais como (i)-(iv) acima referidas.

\section{Termos intencionais em psicologia, sob um novo ângulo}

Ao ser combinada com o modelo da seleção pelas consequências de Skinner (1981/1988; cf. Alessi, 1992; Baum, 2005/2006; Glenn, 1991; Moore, 2008), a abordagem de Ryle ganha mais inteligibilidade. A "postura intencional" permitir explicações e inferências de prováveis comportamentos subsumindo-os a contextos apropriados é algo que pode ser entendido como sendo razão de padrões comportamentais tornarem-se associados a certos contextos ao longo de histórias seletivas. Relações deste tipo são produzidas ao longo de processos de interação ambiental do sistema, seleção de algumas das respostas pelas consequências que delas resultam, e recorrência futura de respostas similares. Assim, por exemplo, um silogismo prático da forma "O rato vai pressionar cinco vezes a barra porque sabe que assim fazendo obtém alimento e quer comer" pode ser entendido como sinalização indireta de uma contingência de reforço (um esquema FR:5), relacionando um histórico de pressionar a barra e um contexto que inclui a barra (além de uma operação estabelecedora correlata). Esta conduta, no passado, sob contexto similar, resultou em obtenção de alimento, aumentando a probabilidade de sua recorrência, de modo que isso permite fazer-se a predição de uma resposta similar. As correlações envolvendo organismos humanos e contextos sociais, constituindo práticas culturais, são frequentemente aprendidas não só pela interação direta com as contingências, mas também por imitação e seguimento de regras (por exemplo, instruções) (Skinner, 1966/1969), de modo que a contextualização promovida pelas atribuições intencionais não pressupõe necessariamente indução a partir da história interativa do indivíduo particular.

Na medida em que não estão para causas do comportamento, embora remetendo indiretamente a elas (as contingências), os termos intencionais não têm um papel explicativo a desempenhar em uma psicologia naturalista. Entretanto, ao assim fazerem, eles podem cumprir um papel heurístico para a descoberta das variáveis controladoras, facilitando, então, a explicação, predição e controle de relações comportamentais.

Isso sob a condição de que não se incorra em erros de categoria, como aqueles associados ao mentalismo. A "postura intencional" de Dennett corre o risco, enfatizado pela tradição behaviorista operante (por exemplo, Baum \& Heath, 1992;
Moore, 2008; Skinner, 1971), de, pelo contrário, deturpar a busca pelas variáveis controladoras, ao atrelá-la equivocadamente a supostas variáveis internas correspondentes. Ou seja, apenas quando empregados livres de pressuposições conceitualmente questionáveis os termos em questão são potencialmente úteis na pesquisa psicológica.

A tarefa da psicologia cognitiva subpessoal de projetar sistemas intencionais e investigar mecanismos de realização das condutas "inteligentes" depende, como Dennett corretamente clarifica, da investigação dos padrões comportamentais de interesse, no âmbito do ambiente maior do sistema. Uma postura individualista, não-externista, que almeje realizar o empreendimento de projeção de sistemas intencionais e explicação de suas condutas fazendo referência tão somente a propriedades supervenientes a estruturas internas, é inadequada, pois os conceitos intencionais dizem respeito às atividades ecológicas dos sistemas. Dennett, no entanto, baseia-se na premissa de que isso ocorre por atributos internos correspondentes realizarem funções de indicação de condições ambientais e alocamento das condutas para a obtenção de resultados, premissa que se mostra falha à luz de ponderações como aquelas levantadas acima.

A projeção de sistemas intencionais e o estudo dos mecanismos de realização e controle destas atividades são (se a premissa mentalista estiver realmente equivocada) melhor conceitualmente vistos como um empreendimento que promove respostas a perguntas sobre como elas se dão, não sobre por que se dão (Rachlin, 1994). O empreendimento, quando bem-sucedido, estabeleceria precondições estruturais para a realização de comportamentos do sistema como um todo, os quais constituiriam critério para as atribuições intencionais relevantes. Os mecanismos internos não são, de maneira alguma, denotata das atribuições intencionais, mas, antes, precondições para que elas possam ser aplicadas. Este vocabulário apenas sinaliza relações que ocorrem, fundamentalmente, como resultado de contingências de reforço. Assim, a psicologia cognitiva subpessoal seria, em princípio, propriamente balizada pelo estudo, em análise do comportamento, das contingências de reforço - e, quando o caso, pela ciência mais geral da seleção do comportamento (Skinner, 1981/1988, 1990) -, embora sem que as atribuições intencionais tenham senão acidentalmente correlatos neurofisiológicos ou similares.

A alternativa aqui sugerida dá razão à objeção de Dennett contra a posição de Churchland pela eliminação do vocabulário intencional em psicologia, mas apenas em parte àquela feita ao eliminativismo de Skinner. De fato, o vocabulário pode ter, tanto para a identificação de padrões de comportamento como para sua predição, certas vantagens pragmáticas. Isso ocorre por os padrões serem produtos de sua história e em confluência com múltiplos fatores, que nem sempre são de acesso simples, e por as atribuições intencionais sinalizarem contingências efetivas. Mas as vantagens em questão têm potencial respaldo apenas sem premissas mentalistas.

\section{Conclusão}

Desenvolveu-se neste artigo um balanço da teoria dos sistemas intencionais no respeitante à sua tentativa de aná- 
lise dos termos intencionais e de legitimação deles em uma psicologia naturalista. Não se trata de um balanço da toda a teoria dos sistemas intencionais (que é parte da filosofia geral de seu autor), uma vez que está voltada também para pelo menos uma terceira grande questão, qual seja, sobre a noção de intencionalidade em geral.

Conclui-se que a abordagem, no que tange ao funcionamento de tais termos, não é tão satisfatória quanto à de Ryle, caso o elemento mentalista que lhe acrescenta for equivocado, como algumas objeções parecem fazer ver. Neste caso, suas contribuições para os delineamentos apropriados, tais como, por exemplo, os traços contextualizador e externista, devem ser entendidos com independência do que este elemento implica. Possivelmente - deixa-se isto parcialmente em aberto aqui - a dimensão funcionalista que lhe acrescenta seja uma contribuição também, livre, no entanto, de referido elemento.

A partir da hipótese deste resultado e de uma combinação da abordagem de Ryle com o modelo da seleção pelas consequências, mostraram-se alguns desdobramentos quanto à segunda questão, dentre os quais o problema de ver-se na projeção de sistemas intencionais o estudo de mecanismos designados pelas atribuições intencionais. Tais desdobramentos, ao fim e ao cabo, tangenciam o próprio modo de entender-se a psicologia.

Não são poucas as avaliações da teoria dos sistemas intencionais, mas grande parte sem indagar suas premissas mentalistas (por exemplo, Brook \& Ross, 2002). Uma exceção é o artigo de Baum e Heath (1992), mas que mantém uma forma de eliminativismo quanto à linguagem intencional e que deixa de considerar os pontos razoáveis da teoria.

O presente trabalho apóia uma eventual adoção desta linguagem em um subprograma de análise do comportamento, como ferramenta heurística (não como vocabulário de base) para investigações em contextos abertos e envolvendo comportamentos relativamente complexos, nisso em concordância com os behaviorismos de Rachlin (1994) e Foxall (2004, 2007). Não há uma incompatibilidade em princípio entre o emprego dos termos intencionais e os objetivos da análise do comportamento, desde que correto e sem erros de categoria, e apenas para as finalidades cabíveis. Porém, na medida em que Foxall assume a abordagem de Dennett sobre estes termos (inclusive a dimensão mentalista), tem-se aqui consequências críticas à sua proposta. Foxall tenta contornar o problema da mereologia que esta enfrenta, mas não está claro que se ele escapa-se do problema, ao conceber que as atribuições intencionais são "revestimentos linguísticos" de estruturas neurais. Além disso, as finalidades para as quais podem ser legítimas em um subprograma em análise do comportamento, e, de modo mais geral, em uma psicologia naturalista, não incluem, sem mentalismo, aquelas sugeridas pelo autor, como a explicação de expressões ('avowals') e o preenchimento de lacunas temporais da seleção ontogenética.

\section{Referências}

Alessi, G. (1992). Models of proximate and ultimate causation in psychology. American Psychologist, 47, 1359-1370.
Baum, W. M. (2006). Compreender o behaviorismo: Comportamento, cultura e evolução (2a ed., M. T. A. Silva e cols., Trad.). Porto Alegre: Artmed (Trabalho original publicado em 2005).

Baum, W. M., \& Heath, J. L. (1992). Behavioral explanations and intentional explanations in psychology. American Psychologist, 47, 1312-1317.

Bennett, M. R., \& Hacker, P. M. S. (2003). Philosophical foundations of neuroscience. Oxford: Blackwell.

Brentano, F. (1995). Psychology from an empirical standpoint (A. Rancurello e cols., Trad.). London: Routledge (Trabalho original publicado em 1874).

Brook, A., \& Ross, D. (Eds.). (2002). Daniel Dennett. Cambridge: Cambridge University Press.

Carvalho Neto, M. (2001). B. F. Skinner e as explicações mentalistas para o comportamento: Uma análise histórico-conceitual (1931-1959). Tese de Doutorado, Universidade de São Paulo, São Paulo.

Churchland, P. M. (1979). Scientific realism and the plasticity of mind. Cambridge: Cambridge University Press.

Cleaveland, J. M. (2004). Beyond trial-and-error in a selectionist psychology. Behavior and Philosophy, 30, 73-99.

Dennett, D. (1969). Content and consciousness. London: Routledge.

Dennett, D. (1978a). Intentional systems. In Brainstorms: Philosophical essays on mind and psychology (pp. 3-22). Cambridge, MA: MIT Press (Trabalho original publicado em 1971).

Dennett, D. (1978b). Skinner 'skinned'. In Brainstorms: Philosophical essays on mind and psychology (pp. 53-70). Cambridge, MA: MIT Press.

Dennett, D. (1987a). True believers: The intentional strategy and why it works. In The intentional stance (pp. 13-42). Cambridge, MA: MIT Press (Trabalho original publicado em 1981).

Dennett, D. (1987b). Three kinds of intentional psychology. In The intentional stance (pp. 43-81). Cambridge, MA: MIT Press (Trabalho original publicado em 1981).

Dennett, D. (1987c). Intentional systems in cognitive ethology: The 'Panglossian' paradigm defended. In The intentional stance (pp. 237-286). Cambridge, MA: MIT Press (Trabalho original publicado em 1983).

Dennett, D. (1991). Real patterns. Journal of Philosophy, 88, 27-51.

Dennett, D. (1996). Kinds of minds: Toward an understanding of consciousness. New York: Basic Books.

Dennett, D. (2007). Philosophy as naive anthropology: Comment on Bennett and Hacker. In M. R. Bennett, D. Dennett, P. M. S. Hacker, \& J. Searle (Eds.), Neuroscience and philosophy (pp. 73-95). New York: Columbia University Press.

Foxall, G. (2004). Context and cognition: Interpreting complex behavior. Reno, NV: Context Press.

Foxall, G. (2007). Intentional behaviorism. Behavior and Philosophy, 35, 1-55.

Glenn, S. S. (1991). Contingencies and metacontingencies: Relations among behavioral, cultural, and biological evolution. In P. Lamal (Ed.), Behavioral analysis of societies and cultural practicies (pp. 39-73). Washington, DC: Hemisphere Press.

Hempel, C. G. (1980). The logical analysis of psychology (W. Sellars, Trad.). In N. Block (Ed.), Readings in philosophy of psychology (Vol. 1, pp. 14-23). Cambridge, MA: Harvard University Press (Trabalho original publicado em 1935). 
Millikan, R. G. (1984). Language, thought, and other biological categories: New foundations for realism. Cambridge, MA: MIT Press.

Millikan, R. G. (1989). In defense of proper functions. Philosophy of Science, 56, 288-302.

Moore, J. (2008). Conceptual foundations of radical behaviorism. Cornwall-on-Hudson, NY: Sloan.

Quine, W. V. O. (1960). Word and object. Cambridge, MA: MIT Press.

Putnam, H. (1960). Minds and machines. In S. Hook (Ed.), Dimensions of mind (pp. 138-164). New York: Collier.

Rachlin, H. (1994). Behavior and mind: The roots of modern psychology. New York: Oxford University Press.

Reichenbach, H. (1938). Experience and prediction: An analysis of the foundations and the structure of knowledge. Chicago: University of Chicago Press.

Ryle, G. (1949). The concept of mind. London: Hutchinson.

Ryle, G. (1979). On thinking (K. Kolenda, Ed.). Totowa, NJ: Rowman and Littlefield.

Ryle, G. (2009). Taking sides in philosophy. In Collected papers, Vol. 2 (pp. 161-177). London: Routledge (Trabalho original publicado em 1937).

Skinner, B. F. (1953). Science and human behavior. New York: Macmillan.

Skinner, B. F. (1969). An operant analysis of problem solving. In Contingencies of reinforcement: A theoretical analysis (pp. 133-171). New York: Appleton-Century-Crofts (Trabalho original publicado em 1966).
Skinner, B. F. (1971). Beyond freedom and dignity. New York: Knopf.

Skinner, B. F. (1974). About behaviorism. New York: Knopf.

Skinner, B. F. (1988). Selection by consequences. In C. Catania \& S. Harnad (Eds.), The selection of behavior (pp. 11-20). New York: Cambridge University Press (Trabalho original publicado em 1981).

Skinner, B. F. (1990). Can psychology be a science of mind? American Psychologist, 45, 1206-1210.

Tanney, J. (2009). Reasons as non-causal, context-placing explanations. In C. Sandis (Ed.), New essays on the explanation of action (pp. 94-111). Hampshire, UK: Mcmillan.

Wittgenstein, L. (1953). Philosophical investigations. (G. E. Anscombe \& R. Rhees, Eds., G. E. Anscombe, Trad.). Oxford: Blackwell.

Wright, L. (1973). Functions. Philosophical Review, 82, 139-168.

Recebido em 17.05.2010

Primeira decisão editorial em 29.06.2010

Versão final em 16.07.2010

Aceito em 20.07.2010 